\title{
Social Production and Drugs Addiction Management among the Young Manual Workers in Northern Benin
}

\author{
Abou-Bakari Imorou* \\ Associate Professor, Department of Sociology-Anthropology, Laboratoire d'Analyse des Dynamiques Socio- \\ Anthropologiques et d'Expertise pour le Développement (LADSED), Université d'Abomey-Calavi (UAC) / \\ Benin \\ *Corresponding Author: Abou-Bakari Imorou, Associate Professor, Department of Sociology- \\ Anthropology, Laboratoire d'Analyse des Dynamiques Socio-Anthropologiques et d'Expertise pour le \\ Développement (LADSED), Université d'Abomey-Calavi (UAC) / Benin
}

\begin{abstract}
The objective of this research work is to analyze the social conditions inducing the emergence and management of performance-enhancing drugs addiction among the young manual workers in Northern Benin. This emerging socio-medical canker which tallies the strategies used to achieved better performance in production is rampant among the youth constantly involved in physical production. Indeed, any production needs physical and mostly human resource for tasks accomplishment. This also contributes to contextualizing labor valuation in a society whereby social success is appreciated in relation with individuals' capacities to produce, accumulate and assume responsibility. Eventually, this is about a context whereby arguments declassifying and stigmatizing largely draw on image of the laziness or incapability to assume anything. As such, family comes to play a crucial role in the constant pressure put on individuals by the social group with a view to urging him to labor. All the same, productivity becomes an individual and collective performance analyzer. From a socio-anthropological perspective, an in-depth description of individual performances and experiences in this study underscores the social impact of the youth drugs addiction. Besides, this research highlights the way those various drugs energize and nurture social unrests generated among the social groups under consideration. The ongoing thinking under cores the places of the social organs, values, perceptions as well as the various shifts noticed in the social life of individuals addicted to drugs.
\end{abstract}

Keywords: Performance-Enhancing Drugs, Tramol, Addiction, Hidden Use, Bénin.

\section{INTRODUCTION}

The social production energized by drugs addiction as analyzed in this paper highlights social and family dynamics through the induced social behavior. Drugs addiction is no longer presented as a conscious and voluntary construct, but rather through its drawbacks effects on family production patterns. This reality can be observed in some social groups. As a matter of fact, the management of material resources generated by the production in some families constantly requires the definition of adaptive strategies. The family, in the African context, stands as the economic institution both in terms of production and consumption (Adepoju, 1999). As such, families adopt many strategies in order to mobilize and raise those resources needed for the survival of its whole members. The social distribution of the production work load is part and parcel of how to organize resources generation. In such a context, one can understand the outbreak of child labor (Imorou, 2006) along the strong pressure put on the youth so as to ensure the fulfillment of their commitment to support to migrate from other family members. Moreover, some young men are even encouraged to migrate in order to get resources they cannot raise at local level (Adepoju, 1999).

Among most of the social groups, there is that trend to assign the leadership to young people in the production of resources. Those are the people active in the various sectors of activity. This remark is quite impressive in the sector of agriculture. In many rural settings in Africa, the young generation is perceived as families' labor force because they are at the forefront in resources production chains. Though the family nuclearization trend seems to downsize families as production units, it still fails to reduce the workload pressure on the active layer of the families. They subsequently design and develop many strategies with the view to taking up the various challenges they face. Among those 
strategies ranges the use of performance-enhancing drugs on purpose of increasing their production capacities. The use of those pharmaceutical and other drugs can be easily noticed since that is done irrespective of the standards (Milhet, 2015:4). As such, from the stage of reception to consumption any diversion might occur regarding the medication. While in western countries medication accompanies the daily life and the life expectancy it has contributed to stabilized the duration (Desclaux \& Egrot, 2015: 10), their consumption in other environments is source of serious public health problems.

\section{The Crucial ISSUe OF Mechanisms Sustaining The Social CONSTRUCT OF AdDiCtion}

The various types of addiction noticed among the young farmers are induced by the social disorganization (Chevalier \& Martinache, 2017) of the conditions surrounding resources production. Such disorganization occurs through a double dynamics: the Changes going along with the socialization at work and the much more pressure on the youth during their empowerment process in the families. The consumption and addiction to performance-enhancing drugs are put forth in this study as the outcome of a learning process. This ignites a reflection which goes along with the sociological interactional tradition of the deviance. According to this tradition, the shift or transition from compliance to deviance cannot be substantiated through the deviant individual but rather in an interactive process during which he is presented as such (Becker, 1985). Social groups identify the consumption threshold which has nothing to do with the individual's level of addiction. That threshold is not similar from one social group to the other. Therefore, one can observe "Consumersaddicted-deviant" and some "Normal-Consumers-Addicted". Both categories are emerge as a result of a process which gradually prompted them to shift from the status of normal producers to that of addicts who cannot produce without having taken performance-enhancing drugs. Unlike the Normaldeviant workers, the addict-deviant has come to a level of consumption which is morally prohibited and punished: consumption of enjoyment. In this context, drugs are no longer consumed with a view to sustaining effort, but rather to meet the consumer's pleasure.

Anyway, nobody indulges willingly in drugs addiction and that does not depend at all on those who, at a given time, have used those drugs. Interactionary sociology used the concept of career (Goffman 1968) in order to analyze slow consumption process during the consumers change their living habits and behaviors. Therefore, the addiction learning appears like a series of reversible consumption behaviors (Chevalier \& Martinache, 2017) changing the individual. The reversible dimension is so important that some people always extensively elaborate on it in order to avoid indulging in any addiction as highlighted in the following statement:

"I still don't understand my friend anymore. We are used to taking Tramol
together. But one day, a senior brother who had taken Tramol several times
in the past, called us and talked to us as follows: "if you want people to
have regards for you, respect you, if you want to be famous, thus you should
leave Tramol. You are still young and Tramol is not good for you. Leave it!
I was personally touched by that advice; that is how I decided to abandon
Tramol. It was seriously hard to live in the beginning. But eventually, I have
definitely succeeded in abandoning Tramol because I want people to
consider and respect me."

The framework and conditions behind the consumption still are the key determining factors in the gradual process of settlement of the addiction. As a matter of fact, many youth self-aid groups are labeled as consumers of those drugs. Those are age groups whose members willingly pool effort together for the benefit of their peers. The member benefitting from the collective assistance in his farming activities is responsible for feeding the whole group members on that very day they go to work in his farm. It also is his responsibility to ensure optimal working conditions because this assistance is rotational and everyone has his turn. According to the respondents encountered, those are suitable environment and occasions for the performance-enhancing drugs intake. Those are equally opportunities for many young men to experiment for the first time the consumption of various drugs likely to enhance their performance with a view to avoiding being ridiculous in the group. Indeed, no rural young man can dear accept to be ascribed the image of lazy and work-shy. And any solution that could be helpful to avoid such a stigma is welcome. 


\begin{abstract}
"My friend $O$. confessed that at his first intake of Tramol dates back to the day we went to work in the farm of one of our mates. We started with that farm and two days later we were to go to another's farm. We are eleven in the group and we rotatively attend the working session. There are many such groups around. The principle is that when we come to someone's farm, we do everything that should be done before leaving at the sunset of that day. The host farmer must provide us with the breakfast, lunch and several in-between energizing breaks. He should thus renew his guests' stock of energy all along the day. So, if you do not provide sufficient food people will not work very well. Thus, people mix Tramol in tea or cereal mixture served early in the morning. Otherwise, the expectation in terms of yield is not attained. And let me tell you that at those occasions, many young men intake drugs without respecting the normal dose. Before, there was a tablet called 'D 10' or '10 Tons' that people used to grind into powder and pour in cereal oak served to workers But now, it is Tramol. The one receiving the members and that fails to do that loses the opportunity". (Statement by A.L a young farmer Madékali, April 2017).
\end{abstract}

Those self-aid groups are the appropriate for strengthening competition among the young men around those croplands and productivity. They present opportunities for the youth to pair and compare with their peers, proceeding with classifying the group from the most hardworking to the least laborious.

\title{
3. Social CONTEXT FOR PERFormance-Enhancing DRUgS InTAKe Resulting IN ADDICTION
}

The mechanisms for drugs intake behaviors are based on a given passivity and / or complicity observed in the social groups of the concerned. The existing scholarships and literature inform that "the friends circle is a major risk factor for the hidden and misused of medication" (Milhet, 201). All the same, "the family environment" is equally involved in that hidden and misused medication and could subsequently play a vital role in youth education on the risks associated to that phenomenon. As such, the young men living in a social environment which offers them the possibilities to socialize with the hidden and misused medication are prompted to use them. Families and more importantly suburbs appear to be areas likely to structure the relationship between the underage subjects and the performance-enhancing drugs.

In several localities of Northern Benin and more generally in the country as a whole, the all-pervading sale of pharmaceutical medicines has been, for a long time, an accepted reality. The coercive methods used during those last years are the outcome of a national political will yet to have a strong local anchorage. As a result, evasion mechanisms are designed to ensure medicines / drugs availability and access. In Northern Benin localities as in other places nationwide, the sale of drugs and other consumables are not socially criticized at local level. As a matter of fact, people do not care about the adverts on the dangerousness of the drugs sold in the streets and the markets. Any coercive policy put in place triggers circumventing strategies among the buyers and sellers. There are very important markets hosting drugs and medicines transaction like that of Malanville. The volume of Drugs trafficking in the market of that town is an indicator testifying that those medicines are of paramount importance in the livelihood of the inhabitants of that locality. Malanville Market plays a crucial role in the medicines supply chain in the Benin-Niger-Nigeria border basin. Despite the prohibition of the black market activities, many health workers and Health Facilities managers are supplied by the Malanville Market Women (Imorou, 2006). Those transactions which are effected in front of many witnesses and potential health facilities' users come to legitimate those black market drugs.

Besides, that market is the source supplying the street and itinerant sellers of medicines in the region. The medicines consumed hiddenly are regarded and classified as black market drugs. The uncontrolled supply modes which apply in this context favor access for underage as in the case of any market goods. The consumption of performance-enhancing drugs appears more and more like a phenomenon which has gained wider space not only in this region of the country, but equally in other regions strongly involved in large scale farming activities. The words or verbal patterns used for portraying the situations of intake of those drugs and justifying their sale seem to trivialize the canker 
and even ascribe it "normal attribute". As such, one can observe the emergence of new normality complying with the changing socioeconomic context which the young people should adapt to

"Here, in our area, there is no other activity apart from farming. And for farming, we do not have any machines or tractors. The cows go about ploughing and the remaining segments are carried out manually. According to you, how can we make it without resorting to use those drugs which give us more strength? Those drugs have no side effects. Very helpful, they rather enable us to increase our farming performance. Anyway, I do take them." (Statement by D., a Farmer in Karimama, June 2017.)

The new dimension of this behavior filters through the statement of many respondents. They definitely think that the societal context has significantly shifted considering the working conditions and mostly the deficit of physical engagement noted among the young men:

\begin{abstract}
"Nowadays, the young men still do not know how to operate the right choice. In our time, there was no drug to swallow before working. But in present days, there is no work you will request a single young man to do for you and he will not ask you drugs money. Even if the work is paid for, the money for buying the drugs is separate. And based on the work size or load you assign them and based on the group size, you have to give between $F$ CFA 100 and 500 for the drugs. It is a matter of common knowledge. They use to say that it is used against fatigue." (Statement by D., a Notable from Guéné, March 2017)
\end{abstract}

The consumption of performance-enhancing drugs is as such viewed like a phenomenon which young men are trend-settingly engaged in. However, there is a kind of spontaneous reaction from the side of elders who set aside of that, although there is no significant blame against the addicts.

The social context of performance-enhancing drugs consumption is also that of their availability in the drugs supply chain also regarded as "fake drugs" the trade-in of which is prohibited in the country. As a matter of fact, the trade-in fake medicine is more and more prohibited in Benin since the second semester of 2016. But it is crystal clear that despite the government's crusade against fake medicines, there still are some illegal trafficking routes for those medicines in all the localities. The prohibition of smuggling and illegal trade-in those medicines still do not bring about its unavailability in the localities. Rather, they are concealed and mechanism of access to them is more complex.

"The fake drugs still exist but in tightly closed circuit. People like you and I
can never go and buy them by ourselves. We are tightly close to the
healthcare givers and the drugs sellers could suspect that we would give
their circuit away to law enforcement authorities. One could never think
that there is a fight against that phenomenon. It still circulates abundantly
but you could not realize it. I also do use it". (Statement by S., former
COGEC member, March 2018)

In spite of the coercion, access to those drugs sis relatively easy for its consumers. The suppliers are well known in all the localities, even though they do not display publicly the medicines any more, the consumers do not come across any special problem to get supplied. In many localities populations do not have access to health facilities. Informal drugs suppliers are therefore the only service providers in the localities. This situation stands as a strong argument about the availability of those drugs in the localities. So, the population has a positive feeling for those suppliers whom they regard as their 'saviors' because they are the only people ensuring the drugs availability.

\title{
4. The Major Arguments Raised to ACCount For the Consumption of Performance- ENHANCING DRUGS
}

The reasons raised by the young men to substantiate the consumption of those performance-enhancing drugs vary according to the respondents. While those who pungently criticize and blame this risky practice think that it emerges as a result of bad companies, those who show tolerance thereto rather associate it to the needs for achieving a good output in physical like farming. 


\title{
4.1. The Bad Company
}

The argument of bad company is often raised by those parents who are surprised to see their sons fully involved in the consumption of those drugs. Since the utilisation of those drugs which influences the young men's output is not a practice imparted through family people believe that only the education received as area-boy or bad companies could be the main causes.

\begin{abstract}
"Nowadays, children are more influenced by the street and their firends than by we who are their parents. They follow their friends and want to copy the mat any cost. This has done it, so I should also do it. And that is how it starts. I have never used any drugs on purpose of any better performance in growing my farm, and I have never told my children such a story. But can you imagine that my son consumes "Salou Zibo"' (Tramol) before working? Where and from whom has he learnt that? Obviously in the street and from his friends. But not from me ... », (Statement by M., Local Elect, Toumboutou, June 2018).
\end{abstract}

The thinking according to which the bad company is an important factor of encounter and consumption of performance-enhancing drugs is widely spread in our localities. It emerges as a criticism against the forum of sociability of young men. Indeed, those young people often belong to groups of friends with whom they meet at the end of the day outside the family circle. They set up high-risk peers groups likely to develop some behaviors which might get out of any family control. Those public forums which are widely spread in the Sahelian zone are perceived as venues of sociability among individuals belonging to the same generation but also venues of expression of various behaviors. Those venues witness the initiation of young people to many behaviors such as the one of performance-enhancing drugs consumption. This reality is so tangible as those spaces are the very places where those young people share tea and other foods. Those are places where they tell each other their success stories, failures and their projects, etc.

"There is a friend of mine with whom I share everything. But from a given
time, I still do not understand him anymore. When time comes to relax, I
always am the only one resting; I was the first, and even the only one really
feeling tired and who obviously needs to res. But I also do remember that
my friend used to tell me every morning that he suffers from malaria and
that he has to take his medicine. So, he always takes a medicine every
morning. What is that malaria type which is treated like that for about two
weeks? Without that medicine, he was always the first to feel fatigue. I
finally understood that he was taking me for a fool. One morning, I told him
that I was not feeling fine at all, and that I needed one of his tablets. He
gave me it. Let me tell you that I worked that day like an iron. I did not feel
any tiredness. From that day, I cannot refrain from using that medicine
anymore. We used to take two tablets at the beginning. But for the past
crops season, even three (03) tablets don't generate the desired effect ...",
(Statement by T., a Young Farmer in, Malanville, May 2018).

\subsection{The Needs to Achieve Good Output}

Many among those who consume performance-enhancing drugs and who confess their social behaviors during the interviews justify them through the needs for a better output in their farming activities. The physical nature of that activity is always the major arguments raised by the addicts. And here, the concern is seeking conditions for improving the yield. Farmers, cattle breeders, truck farmers and other manual workers use to adopt such means in order to work without feeling tired, putting off their fatigue threshold.

"One was complaining about fatigue and the remaining work load when my
tea man told us that there is a medicine annihilating fatigue and renewing
strength. He proposed us to try it the following day. Since we were looking
for a solution, we agreed with his suggestion. On the following day we went
to his place at daybreak He served each of us one cup of the tea at F CFA
100 each and allowed us to come back to pay when we return from the farm. 
We entirely ignored the ingredients he put in the tea cups. We worked that day without feeling neither tired nor hungry until sunset. We were still feeling strong when we returned home in the evening. You even cannot imagine that we have been to work in the farm. When we came back, the Tea man revealed that he put in our cups a medicine which generated all that energy and joy of work in us. He availed his service to us saying that we could come back at any time we feel the need to do some work without feeling any fatigue like the Niger tiredless "Salou Zibo". From that day on, we always go to that Tea man. Depending on what we want, either he served it in the tea or he gave us the tablets to swallow directly." ", (Statement by B., A Young Laborer Karimama, May 2018)

Here, efficiency is measured through the duration of the activity without fatigue. Physical resources are mobilized and the fatigability threshold is related to the limits that everyone can afford. With the consumption of those performance-enhancing drugs the normal fatigability threshold is postponed and the output is more important in terms of farmed land for the farmers and legumes producers, in terms of the time spent in the grazing land for the young herd men, and in term of accomplished work for the other laborers and manual workers.. So, the young men organize and plan their consumption based on their work load and their habits, as this respondents points out:

\begin{abstract}
"They set up laborers groups to go and work for people in order to gain some money. Each member is remunerated according to the work accomplished by him. For getting much, you must have worked a lot. The young men are bound to resort to thos doping drugs", (Statement by Z, Caregiver)
\end{abstract}

\title{
4.2.1. The First Intake, Dependency and Drift into Addiction
}

The stories about the first intake refer to disparate encounters governed by a logic more or less common to all the stakeholders: the awareness campaign stipulating that such intake definitely increases the capacities of those who perform well. The impressions mentioned are not always those of assurance or predictability of the output after consumption. If the objective of the consumption is more or less precise, the reality is that there is, at this stage, an atmosphere of fear among consumers. Generally, for some, this fear remains the major argument for forgoing the consumption when it encounters an openly hostile and highly deterrent social environment. It is very important because the addict subject is young and still remains under strong family control as dependent. It follows from this information that though parents often urge their children to make effort they do not ask them to intake any doping medicines for the sake of performance. As the respondent below points out, there is even a fear of the reaction that parents might be aware that their children are performance-enhancing drugs consumers:

"The first time I was afraid that my father would detect it. He could beat me. So, I even could not take the risk of doing so at a time or place that may attract suspicion. So I took the drugs without allowing him to suspect anything. But once I took that, I felt so strong and happy. I decided to accompany him in his farm, and for the very first time, my father was very proud of me in the farm because I worked beyond his expectations, I worked more than I usually did. He never stopped asking me what has changed, what motivated me $t$ work so hard. I couldn't answer him. The day he discovered that I was taking Tramol, he told me how he was highly disappointed. I was discouraged and wanted to stop but I couldn't. I was used to it. I stopped for two days but the performance in the farm declined considerably and I had to pick up again against my will" (Statement by Z.N., Garou, May 2018).

These statements unveil a kind of ambiguity in the behavior of the stakeholders involved in the phenomenon. Depending on the case, reactions may vary from adamant refusal with brutal forms of coercion to tacit resignation in which the blame is only verbal. In families where addictions are observed, the trend is a tacit resignation. The arguments of the lack of firmness in the blame and reproach expressed in the family circle remain the observation of a greater investment at work. 
From the respondents' point of view, the long-lasting and sustained use of these medicines is the main cause of dependency. But stigma is much more put on addiction consumption for enjoyment. The consumption environment is thus governed by some social factors that may or may not be favorable to the acceptance of consumption. On the scale of values and counter-values, we note the very high valuation of the production effort. The use of doping drugs is in no way presented as a cheating in the production effort, as it is in sports competitions in particular it is on the contrary in complicity with labor. Labor is valued here among men as it refers to the ability to generate resources to assume their family's responsibility. It should be noted that these are patrilineal societies where the male head of household has a great responsibility for the availability of resources and family survival. Adolescents or young adults are introduced to the value of production efforts. In the current discourse there is the idea that the "elders" hold income to support effort that does not fall within the scope of the doping register described here. The situation is thus presented by young people as the knowledge retention that allowed the "elders" to be efficient in the production effort. These recipes, according to the socalled "elder" people, require a lifestyle that is difficult to observe among young people:

\begin{abstract}
"We were not consuming everything that people are consuming now that makes them vulnerable. We used to have millet porridge for breakfast without sugar. Sugar kills slowly. We didn't eat cube (Maggie aroma) and neither did the tablets. We took decoctions of plants that were often bitter and we were healthy. Our women gave birth without suffering and our young people did not need tablets to work. And then we worked together for the whole house, it wasn't every man for himself. (S.L. Village Chief, June 2017).
\end{abstract}

\title{
4.3. Observations and Perceptions of Addiction at Local Level
}

While the concept of addiction refers to a whole process of enunciation that attempts to shape a heterogeneous set of behaviors related to uncontrolled consumption of drugs for various purposes. When Drugs Consumption increases performance, when it becomes uncontrolled, induces a phenomenon (addiction) that is not locally named. There are no local concepts to specifically address this form of addiction. The words used in the speeches are highly stigmatizing: "drug addicts". The choice of this word seems to reflect the complexity of the figures in it. It includes both consumers of doping medicines who have fallen into jousting addiction and consumers diverted from other nonpharmaceutical medicines such as "solvents", "dry Soukoudaï" which have the same jousting effects. However, addiction is reflected in the descriptions of socially experienced situations by interviewed observers. They state them in more or less identical ways with expressions that refer to the natural inability to cope with certain tasks, certain social challenges. They also link it to the discomfort perceptible in the addicted subject who shows his inability to do any work without taking the drug ahead. This inability therefore generates the necessity to seek alternatives in order to meet some social constraints. Even if at local level people are unable to explain the phenomenon of dependency, it still remains a social canker calling for constant. The case descriptions clearly show that there is a real awareness of the dependency phenomenon because populations link behaviors to the consumption of indexed and explicitly named medicines. The social observation of dependency is linked to the social extent of consumption and the forms of sociability of consumers. There is a widespread perception that the number of young consumers of doping medicines is significant even if statistics are not available to support this view. Popular perceptions also convey the feeling that the number of these consumers who are dependent is growing and makes this problem a social and then a scientific concern. In the areas concerned, the speeches are evocative:

"Young people today know nothing but Tramol. B.R. is one of many. He is
not the only one. If the police could come and pick up all the Tramol
consumers, it would be a great relief. In this village, Tramol has made it
impossible for two brothers to talk calmly anymore. For nothing, we bring
you two brothers who stabbed each other. What is this problem that only the
knife solves? I'm tired. I'm tired. I no longer want to deal with the business that
Tramol creates I am tired (D. a neighborhood chief, Karimama, May 2018.

If the ordinary consumption of those medicines results in a one-off improvement in production capacities, the effects of these medicines are also assessed in terms of the recurrence of crises that 
they generate between young people in sociability groups and, above all, the violence observed in their behavior. Some heads of households and other social elders only become aware of the changes in the behavior of these young people once they become violent. Beyond that, there are a series of degrading perceptions for the image of the dependent consumer. Many of them are moving from the status of valued and respected producers to a highly stigmatized status, as highlighted below:

\begin{abstract}
"Since he started taking Tramol, he no longer respects anyone and listens to anyone. This product he's taking has made him sterile. He is married, his first child is 4 years old but his wife has not become pregnant since. Tramol makes its consumers sterile but they don't know. All those who consume Tramol a lot in the village, have all become infertile, their last children are 5 years old, 6 years old but their women have no longer become pregnant. They are full in the village. We talked to B., we had a family meeting to talk to him, to explain that it's not good for him to consume Tramol like that and that he just has to leave. That same night, B. wanted to throw himself into the well because his family asked him to leave the Tramol. He would have killed himself if we hadn't held him back. He says he takes the Tramol to work but he doesn't do anything except fight everywhere".
\end{abstract}

The recurrence of the findings of the integration of these medicines into the daily lives of populations, the spontaneous use of these medicines to support the physical effort of young producers, and its trivialization indicate the extent of its establishment in many villages. The situation described indicates that almost all rural production areas are finally aware of the use of these medicines. The time of recognition of an individual's consumption of performance-enhancing drugs often does not correspond to the beginning of his or her consumer career. Indeed, the consumer career makes it possible to identify the cycles of changes in personality that occur as a result of this career and the changes in the system of representations by which the individual becomes aware of himself (Goffman, 1968). For Goffman, this concept of career allows him to express the social context in which the life of any individual takes place. Young consumers are only mentioned as such as soon as they begin to slide into the addiction that leads them to a progressive social downgrading.

For many respondents, addiction only becomes an object of concern as soon as it produces "abnormal" behaviors: "when he takes it at a given time he trembles", "he sometimes falls and drools", "he does not eat when he takes it", "he is amorphous and can do nothing" etc. These cases seem to be the extreme behaviors induced by addiction. In ordinary times, expressions on addiction highlight the fact that there are people who cannot work if they do not consume doping medicines. Here the assessment is made in relation to the practical utility of consumption. The sector of activity is by no means indexed, even if it remains characterized by the use of physical force. Whether the work is for the direct benefit of the individual or not, when the conditions of its realization require that he make use of any medicines likely to support his effort and that this becomes indispensable for the accomplishment of the task the respondents conclude to addiction.

\title{
4.3.1. Social Care and Support Measures to Address Performance-Enhancing Drugs Addiction
}

It also a matter of common knowledge that if the social context is to a large extent produce dependency by valuing and upgrading the figures of hard-working producers without any rigorous check of the conditions surrounding production process, the affected subjects close relatives shall mobilize so as to manage dependency. Indeed, it is the close relatives who primarily experience the drawbacks and adverse effects of the addiction. And they are the ones who take measures to solicit the assistance of traditional healers:

"I am treating Tramol addiction, cigarettes and Soukoudai. When the person becomes dependent on Tramol, I treat it. For Tramol, we leave it in the henhouse for seven days and on the eighth day we give it to the person concerned and he drinks, if it's the cigarette it's like that too... There are also the chicken droppings. There are chicken droppings that are yellow in appearance. We take this yellow drop. If it's Tramol, you take the Tramol tablet, you pass this dropping over the Tramol tablet and when it gets dry we give it to the person concerned. The person will vomit until they want to 
vomit their intestines and it's over when they smell the smell they vomit. There is also the cigarette, the part you put in your mouth to smoke, that's what you pass the manure on and when it's dry you light it up and the person concerned smokes it and it's over. In all cases, the yellow chicken droppings must be fresh (wet). There are some leaves and roots that I mix, accompanied by incantatory words and when one prepares and the person drinks and washes with it will stop", (G, Chairman of the Karimama Healers' Association, May 2017).

The forms of addiction that mobilize healers' efforts are those showing some pathology and which are recognized as such by the socio-professional group of the addict individuals. In general, the need for care is felt when the addicted individual's behavior challenges the family circle who asks him unsuccessfully to stop taking such drugs. When addiction is experienced as pathology the family environment rises up in arms to manage all the aspects of misfortune. For young people themselves, the awareness of addiction becomes reality when they can no longer control the pace of consumption.

"Following anger from my parents who threatened me, I tried to leave. And I really promised I wouldn't take Tramol anymore. But when I try for a few days I don't arrive. It's like I can't give up on this anymore. When I make the effort, it's two days, I start taking it again. Otherwise I feel a serious lack and I have no motivation to do anything. My friend with whom I was taking the drugs was able to abandon thanks to his aunt who helped him" (A young addict, 21 years old, Timbuktu, May 2017).

Awareness of addiction is often also related to the amount of Tramol tablets that the individual must take to feel the desired effects. According to the respondents, this number increases with the level of addiction.

"They go from two pills to three, four, six... young people alone, without the help of parents or adults, don't really get by. For example, I have a friend with whom I used to take Tramol. We were taking that in the meantime, yes, Tramol, I was taking that, but I gave up, didn't I? So I told him that the consumption is too much and that he only has to do it slowly, slowly, so he knows himself consciously that it is not good, but as he became dependent, he couldn't leave it all at once and I told him to leave it alone that it is not good. He himself knows that it's not a good thing every time I tell him that he says he understood that he's going to leave, he's not going to take it up again, two or three days later he falls back into it..." (B, Community Worker, Malanville, May 2017).

In the localities investigated and more generally in the country, dependency is not experienced as an important public health pathology involving public care services. These issues are addressed and treated according to the case, either by traditional family circle or in Mental or Psychiatric Health Centers for the most serious ones. For the latter, we observe the mobilization of institutions of deprivation where the individual enters an inadequate state and exits into a state rehabilitated to society (Goffman, 1968). However, if some dependencies are not experienced as deviance because of the social utility of the individual concerned, some are. The management of cases considered deviant involves a set of actors with multiple strategies and specific knowledge.

"We talked to I. Tired! It didn't work. He was deprived of money, it didn't work. Sellers were warned that if I. comes to buy Tramol or other medicines and they sell it to him and something happens to him, they are the ones who will be arrested. But it didn't work too. Now, we trust in God and pray that he will get by" (K. a brother of a young addict, Guéné, May 2018).

While the etiological references of addiction refer to the excessive consumption of doping medicines, the causes of this consumption are often diversified in local discourses on the phenomenon. Indeed, there are those that are linked to the sole will of the individual while other causes fall within the logic of imputation (Augé \& Herzlich, 1984) and persecution. In many cases the parents of the dependent consumer do not link misfortune to a natural cause. If the product responsible for the forfeiture is 
known and consumption stigmatized, the will of the individual consumer is beyond reproach. The arguments that justify consumption are therefore not sought in the personal will of the individual consumer but in the invisible manipulation to which he is subjected. In this case, we find ourselves in situations where the will to consume is manipulated by exogenous forces. From this point of view, addiction is not a simple psychological phenomenon but the result of human action, as these words underline:

\begin{abstract}
"Sometimes people do not consume these medicines voluntarily. There are cases where there is a hand behind it. They need help and we have to help them get out of it. I'm doing it. Last year there was a lady who lived in Niamey and whose brother is here in the village. I wrote some Koranic verses that I washed and put in a can for them. Right now, the guy, if he smells Tramol or drinking, he vomits. He no longer drinks, no longer smokes and no longer uses Tramol", (A., Traditional Healer, Karimama, March 2018).
\end{abstract}

As is the case with most mental illnesses (Goffman, 1968), consumers who are dependent on performance-enhancing drugs do not go to care on their own. In general, a family member or acquaintance makes the decision to support them in a therapeutic process.

\title{
"...Addicts never come on their owns It is the parents who go to the healer. They see that if they don't do something, their son will go mad and that's when they go to the healer to ask him for help", (G, President of the Karimama Healers Association, March 2018).
}

In all cases encountered in the field, healers and other witchdoctors are the preferred remedies. This trend is of course related to the perception that addiction does not refer to an ordinary pathology.

\subsubsection{The Social Groups as Producers-Managers of Youth Addiction Dilemma}

The action of consuming performance-enhancing drugs follows a social dimension which remains understandable in terms of its linkages with the meaning the consumers ascribe to their actions and which singularly refers to the need to embody a valued social identity: the one of the efficient producer. It is therefore understandable that social relations significantly influence this emerging behavioral construct among the young people. Akindès (2003, pp. 10-11) mentions in this regard the preponderant influence of social groups in the process of self-representation and others. He believes that "African societies produce systems of thoughts and practice, values and norms governing individual and collective behavior in order to bring together the different social components". Young people's motivations are strengthened by mobilizing individual rationalities and integrating elements of a social environment conducive to behavioral observation. Beyond the encounter between young people and the performance-enhancing drugs, there are those kinds of personal stories made up of hesitation, several attempts, avoidance, encouragement, decision to take and gradual shifts.

Consumers who acknowledge taking doping medicines while controlling doses and frequency of use appear to be numerous in view of the social extent of the phenomenon in some localities. In general, the personal stories of young people's encounters with these medicines thus show shifts from "normal" to "pathological" which remain progressive with thresholds that are always shifting. Goffman (1968) recommends that the objective functions of an institution (the family here) not be confused with the rationalizations observed among its members, which express themselves in a situation related to dependency. These rationalizations replace the actual hardships experienced by social agents within the framework of the objective issues that drive their drama. The most marked social shifts are towards forms of dependency that are highly stigmatized because they undermine the basic functions of family protection. And it is only now that the family environment is mobilizing to manage the misfortune that has arisen. The decision to seek care is only made when the threat of a psychiatric illness is felt in the dependent subject. It is usually taken by the parents.

The phenomenon of young people's addiction to performance-enhancing drugs is analyzed here against the theoretical backdrop of this dilemma of drift in the search of fame and performance in families where resource production is manually conducted in contemporary Benin. The social frameworks and dynamics crossing through them highlight variability in the relationship to social 
norms. That leads to a context whereby young people, moved by the dynamics of achieving social identities geared towards the valorization of labor generate changes that move the cursor of socially acceptable norms. The result is a social cursor theory that captures what is socially unacceptable at one time but likely to become so in other circumstances within the same social group. In his pathological analyses (Durkheim, 1987), he has already highlighted the particular situations in which the collective rules that govern individual behavior slacken or remain in contradiction with each other. Here the conditions of resource production undermine social control. And the socially-acceptable cursor is linked to the variability of the relationships that populations have with norms. The thresholds are shifting. It is crystal clear that in the analysis of this performance-enhancing drugs addiction and the social context of its emergence, necessity can shake up social morality and make it move to the point of relaxing judgments about what would once have been entirely rejected.

The social support environments preparing the ground to the emergence of performance-enhancing drugs addiction are varied but to a large extent they refer to places where the need to increase human capacities is felt as moral burden. Generally, those are consumptions driven by the need for greater labor in the production sector at stake. There is a kind of social identity (Goffman, 1963) that refers to a set of characteristics that the social group expects from the individual and which is also reflected in the human ideal expected of him at the end of his socialization, which permanently inscribes the permanent provisions that take the form of habitus (Boudieu, 1984) and that guide the individuals behavior. The young man must therefore embody the image of a hardworking man, capable of producing at the cost of effort.

The social frameworks of consumption are not necessarily affected by socially constructed norms. While social values are not generally conducive to deviant behavior, which is the product of psychotropic drug use, it should be stressed that there is no significant stigma attached to the availability of medicines in the social environment of individuals and even their controlled consumption. There is as if the implicit aspect of the normative framework refers to an environment where the individual must be able to set limits for himself to embody a social identity expected of him. However, addiction, the consumption of coveted objects beyond any control, always follows a more or less classic progression with clearly identified phases. The march towards the embodiment of this social identity produces devalued identities or forms of social downgrading that lead to gender discourse:

"B. makes us ashamed. We want to save him. We are all in the village, we
see and know very well who sells him the Tramol. We went to him and asked
him not to sell any more. But it didn't work. The fool there keeps providing
it to him. Normally, the police would come and break all these salesman's
huts. They are there as sellers of cookies, candy, cubes and others but they
hurt many people and their families by selling Tramol and Soukoudai to
people. Even if the police come they will not find anything in the shops, they
will search but they will not find anything. Even the buyers when they go,
they don't see anything, it's the seller who goes to an anteroom to bring that.
That's a pity! "(Comment by C.K., Karimama, April 2018)

From this point of view, the stigmatized addicted individual is blamed for not being able to control the impulses that drive him/her to consume those drugs. Tensions with the drifts in the use of doping medicines are all the stronger as those who fall into enjoyable use are more and more numerous and find substitutes for Tramol when they no longer have access to it. The successive and sustained consumptions that lead to addiction are presented by the respondents as a succession of reversible behaviors that gradually change the individual. Dependency is therefore not systematic for all consumers and is not the responsibility of all those who have at some point used these medicines. It is the work of those who have not been able to set limits. It can be seen that not all those who are dependent are systematically stigmatized. The entry into stigmatized dependency is the result of those who have shifted from consumption for productive purposes to enjoyable consumption. The way they are viewed changes as a result

\section{CONCLUSION}

Depending on the level of consumption and the threshold of addiction, this phenomenon leads to the dilemma bringing together the individual, the drugs and the social universe of consumption. Indeed, 
those three dimensions are predominant to fully understand the above-described phenomena. As a result, one is prompted into some social frameworks that evacuate the primacy of drugs over the individual and relativize the individual willingness to consume those medicines. Neither the drugs, nor the addict individual can bear alone the arguments explaining the noted phenomenon. The analysis reveals that the focus on any of the two or even the search for explanations from the single side which could induce the restriction of the reality as perceived by the young people.

A holistic approach is therefore required if one should cast wide and fully understand the dynamics that of consumption of those performance-enhancing drugs and the management of its addiction. The hardworking consumer is not even regarded as a cheater as opposed to the case with doping in sports competitions. However, there is a strong stigma against those consumers who are constantly enjoying life only through addiction to those drugs. They no longer consume those medicines for the purpose of working and achieving good performance but rather in the search of the effects they draw from them. However, this stage is the result of the gradual threshold shifts from the labor-driven stages which are not subjected to any criticism to the stigma stages.

\section{REFERENCES}

[1] Adepoju, A.. W. (1999). Les Mutations de la Famille Africaine ». In La famille Africaine.

[2] Politiques Démographiques et Développement. Paris: Kathala, pp. 59-84.

[3] Akindès, F.(2003). Le Lien Social en Question dans une Afrique en Mutation. In

[4] Souverainetés en Crise. Paris: L'Harmattan et Les Presses de l'Université Laval, pp. 379-403.

[5] Augé, M. \& Herzlich, C. (1984) Le Sens du Mal. Paris: Éditions des Archives contemporaines.

[6] Becker, H. (1985). Outsiders. Paris: s.n.

[7] Boudieu, P. (1984). Question de Sociologie. Paris: Edisiotns de Minuit .

[8] Chevalier, B. \& Martinache, I. (2017). Déviance et Contrôle Social. Clamecy: Bréal.

[9] Desclaux, A. \& Egrot, M. (2015). Anthropologie du Médicament au Sud. La

[10] Pharmaceutication a ses Marges. Paris: L'Harmattan.

[11] Durkheim, E. (1987). De la Division du Travail Social. Paris: PUF, Collection "Quadrige" .

[12] Goffman, E. (1963). Stigmate. Les Usages Sociaux du Handicap. Paris: Edition de Minuit.

[13] Goffman, E. (1968). Asiles: Etudes sur la Condition Sociale des Malades Mentaux. Paris: Editions de Minuit.

[14] Imorou, A.-B. (2006). Cliniciens Versus Santé Publique: Socioanthropologie de la Mise en Oeuvre d'une Réforme Santaire au Bénin, Marseille: Thèse de Doctorat EHESS.

Citation: Abou-Bakari Imorou. " Social Production and Drugs Addiction Management among the Young Manual Workers in Northern Benin" International Journal of Research in Sociology and Anthropology (IJRSA), vol 5, no. 4, 2019, pp. 1-12. doi: http://dx.doi.org/10.20431/2454-8677.0504001.

Copyright: (C) 2019 Authors. This is an open-access article distributed under the terms of the Creative Commons Attribution License, which permits unrestricted use, distribution, and reproduction in any medium, provided the original author and source are credited. 